\title{
A molecular expression signature distinguishing follicular lesions in thyroid carcinoma using preamplification RT-PCR in archival samples
}

Karen M Denning ${ }^{1}$, Paul C Smyth ${ }^{1}$, Susanne F Cahill ${ }^{1}$, Stephen P Finn ${ }^{1}$, Eilish Conlon ${ }^{1}$, JingHuan $\mathrm{Li}^{1}$, Richard J Flavin ${ }^{1}$, Sinead T Aherne ${ }^{1}$, Simone M Guenther ${ }^{2}$, Astrid Ferlinz ${ }^{2}$, John J O'Leary ${ }^{1}$ and Orla M Sheils ${ }^{1}$

${ }^{1}$ Department of Histopathology, Trinity College, University of Dublin, Dublin, Ireland and ${ }^{2}$ Applied Biosystems, Foster City, CA, USA

\begin{abstract}
Follicular variant of papillary thyroid carcinoma is a lesion that frequently causes difficulties from a diagnostic perspective in the laboratory. The purpose of this study was to interrogate a cohort of archival thyroid lesions using gene expression analysis of a panel of markers proposed to have utility as adjunctive markers in the diagnosis of thyroid neoplasia and follicular variant of papillary thyroid carcinoma in particular. Laser Capture Microdissection was used to procure pure cell populations for extraction. In addition a novel, multiplex preamplification technique was used to facilitate analysis of multiple targets. The panel comprised: HLA-DMA, HLA-DBQ1, CD74, CSNK1G2, IRF3, KRAS2, LYN, MT1K, MT1X, RAB23, TGFB1 and TOP2A, with CDKN1B as an endogenous control. Expression profiles for each target were generated using TaqMan ${ }^{\mathbb{B}}$ Real-Time PCR. HLA$D M A, H L A-D Q B 1, M T 1 X, C S N K 1 G 2$ and RAB23 were found to be differentially expressed $(P<0.05)$ when comparing follicular adenoma and follicular variant of papillary thyroid carcinoma. Comparison of follicular adenoma and follicular thyroid carcinoma groups showed significant differential expression for MT1K, MT1X and $\operatorname{RAB23}(P<0.05)$. Comparison of the papillary thyroid carcinoma group (classic and follicular variants) and the follicular adenoma group showed differential expression for CSNK1G2, HLA-DQB1, MT1X and RAB23 $(P<0.05)$. Finally, KRAS2 was found to be differentially expressed $(P<0.05)$ when comparing the papillary thyroid carcinoma and follicular thyroid carcinoma groups. This panel of molecular targets discriminates between follicular adenoma, papillary thyroid carcinoma, follicular variant of papillary thyroid carcinoma and follicular thyroid carcinoma by their expression repertoires. It may have utility for broader use in the setting of fine-needle aspiration cytology and could improve the definitive diagnosis of certain categories of thyroid malignancy.

Modern Pathology (2007) 20, 1095-1102; doi:10.1038/modpathol.3800943; published online 27 July 2007
\end{abstract}

Keywords: follicular variant papillary thyroid carcinoma; molecular marker; preamplification

Thyroid carcinoma is the most frequently occurring endocrine malignancy. Well-differentiated thyroid tumours of follicular cell origin are sub-divided into follicular adenoma, follicular thyroid carcinoma and papillary thyroid carcinoma. ${ }^{1}$ Approximately $80 \%$ of thyroid carcinomas are papillary carcinomas. ${ }^{2}$ Papillary thyroid carcinoma is defined as a malig-

Correspondence: Professor OM Sheils, PhD, Department of Histopathology, Institute of Molecular Medicine, Trinity Centre for Health Sciences, St James Hospital, James Street, Dublin 8, Ireland.

E-mail: osheils@tcd.ie

Received 25 May 2007; revised and accepted 29 June 2007; published online 27 July 2007 nant tumour showing evidence of follicular differentiation and characterized by distinctive nuclear features. ${ }^{3}$ Because papillary structures may occasionally be found in follicular adenoma and follicular thyroid carcinoma, the diagnosis of papillary thyroid carcinoma ultimately depends on its nuclear features, that is ground glass appearance, irregularity of nuclear contours, grooves and pseudo-inclusions. ${ }^{4}$ The diagnosis of papillary thyroid carcinoma does not simply depend on the presence of these nuclear features but the extent to which they are present in 'a significant proportion of the neoplasm'. ${ }^{3}$ The lack of appreciation of the diagnostic features of a papillary thyroid carcinoma, particularly in encapsulated tumours, may either lead to 
the misdiagnosis of a follicular thyroid carcinoma or that of a benign follicular adenoma. ${ }^{4}$

The follicular variant of papillary thyroid carcinoma is found in $9-22.5 \%$ of patients with a papillary thyroid carcinoma. ${ }^{1}$ Follicular variant of papillary thyroid carcinoma is composed predominantly by follicles, which are lined by cells that have the nuclear features of papillary thyroid carcinoma. ${ }^{5}$ Follicular variant of papillary thyroid carcinoma may cause (if the nuclear features of papillary thyroid carcinoma are insufficiently appreciated) severe problems in discrimination from follicular thyroid carcinoma or follicular adenoma. Characteristically, follicular adenoma is encapsulated, cellular and has a relatively uniform follicular pattern. ${ }^{6}$ Follicular thyroid carcinoma is unifocal, encapsulated and metastasizes directly to distant organs. ${ }^{1}$ Microscopically, follicular thyroid carcinoma most often has a microfollicular pattern and may resemble a cellular follicular adenoma. ${ }^{6}$

Because cytology cannot always accurately discriminate between benign and malignant follicular thyroid tumours, patients displaying a follicular thyroid lesion are advised to undergo surgery, usually a hemithyroidectomy, to verify an accurate diagnosis and to decide additional treatment. Those who ultimately reveal a carcinoma are generally advised to undergo a second operation, a complete thyroidectomy. ${ }^{7}$ However, only $10-20 \%$ of these undetermined nodules are malignant on histology. ${ }^{6}$ Patient management would be greatly enhanced by additional diagnostic tests. There is a role for accurate molecular markers that can further classify problematic groups in thyroid malignancy.

The panel of markers employed in this experiment were chosen from a microarray study previously carried out by our group. ${ }^{8}$ Significantly expressed targets in the panel included members of the metallothionein family $M T 1 K$ and $M T 1 X$, casein kinase I $\gamma 2$ (CSNKIG2) a serine/threonine protein kinase thought to be involved in insulin receptor and platelet-derived growth factor receptor signalling. The panel also included RAB23; a small GTPase involved in hedgehog signalling, MHC class II genes HLA-DMA and HLA-DQB1, and KRAS a member of the RAS family, whose mutations have been widely demonstrated in thyroid carcinoma.

\section{Materials and methods}

\section{Tissue Samples}

Thirty-one classic papillary thyroid carcinoma, 14 follicular variant papillary thyroid carcinoma, 10 follicular thyroid carcinoma and 17 follicular adenoma $(n=72)$ cases of formalin-fixed paraffinembedded thyroid samples were analysed. These cases were accessioned from archives dating from 2000 to 2005 at St James Hospital, Dublin. The study had the approval of the St James Hospital and Adelaide and Meath Hospital research ethics committee. Haematoxylin and eosin (H\&E) sections were reviewed by a histopathologist (SF) and classified according to a recognized system. ${ }^{5}$ Corresponding paraffin blocks were then collected from the archives of St James Hospital.

\section{Laser Capture Microdissection}

Seven micrometers thick sections were cut using a microtome (Microm HM 325, Medical Supply Co. Ltd, Ireland) from each paraffin block, mounted on uncharged slides, dewaxed and H\&E stained (Tissue-Tek DRS 2000 Autostainer, Sakura, CA, USA). Pure populations of thyrocytes were obtained from each section by laser capture microdissection using the PixCell II System (Acturus Engineering Inc., CA, USA). Laser capture microdissection produces low yet accurate yields of RNA (yields in the range of $5-63 \mathrm{ng} / \mu \mathrm{l}$ were achieved in this study). Cells were captured according to a standard protocol: laser spot size $=30 \mu \mathrm{m}$, pulse power $=40 \mathrm{~mW}$, pulse width $=1.5 \mathrm{~ms}$, threshold voltage $=285 \mathrm{MV}$. The total number of pulses in each case was approximately 700 (range $=500-1200$ ). After microdissection the Capsures (Capsure ${ }^{\mathrm{TM}}$ Macro LCM caps, LCM 0201, Techno-Path Ltd, Ireland) containing the homogenous cell populations were placed in a sterile microcentrifuge tube ready for RNA extraction.

\section{RNA Extraction}

RNA was extracted using the Absolutely RNA $^{\circledR}$ Formalin-Fixed Paraffin Embedded Kit (Stratagene, CA, USA), according to manufacturers' instructions, with the exception of the tissue deparaffinization and dehydration step of the protocol as the sections had been deparaffinized during H\&E staining. The protocol recommended the use of two $10 \mu \mathrm{m}$ thick sections; however, the quantity used in this experiment was sufficient ( $\sim 150$ cells in some cases). Purified RNA was eluted in $30 \mu \mathrm{l}$ volumes and the nanogram concentration per microlitre was verified using a NanoDrop spectrophotometer (ND-1000, Labtech International, UK).

\section{cDNA Archiving and PreAmp Synthesis}

The RNA was reverse transcribed to single-stranded cDNA using a High Capacity cDNA Archive Kit (Applied Biosystems, Foster City, CA, USA) in $50 \mu \mathrm{l}$ reactions. Reactions contained $5 \mu \mathrm{l}$ of buffer $(10 \times)$, $2 \mu \mathrm{l}$ of deoxynucleotide triphosphate $(25 \times), 5 \mu \mathrm{l}$ of random primers $(10 \times), 5 \mu \mathrm{l}$ of multiscribe RT enzyme ( $50 \mathrm{U} / \mu \mathrm{l}), 10.5 \mu \mathrm{l}$ of nuclease-free water and $25 \mu \mathrm{l}$ of extracted total RNA $(0.125 \mu \mathrm{g})$. The reactions were incubated at $25^{\circ} \mathrm{C}$ for $10 \mathrm{~min}$ and $37^{\circ} \mathrm{C}$ for $2 \mathrm{~h}$ (Perkin Elmer 9600 GeneAmp PCR system, Applied Biosystems). Laser capture microdissection achieves 
low yet adequate yields of RNA, and a range of $5-63 \mathrm{ng} / \mu \mathrm{l}$ was attained.

Applied Biosystems TaqMan ${ }^{\circledR}$ PreAmp Master Mix Kit is intended for use with very small quantities of cDNA, and increases the quantity of cDNA for gene expression studies. Before running the preamplification reaction, the intended assays (containing primers and probes) were pooled together, as per the manufacturer's instructions with $1 \times$ Tris-EDTA (TE) buffer in a $0.2 \times$ pooled assay mix. The preamplification reaction was performed in $50 \mu \mathrm{l}$ reactions containing $25 \mu \mathrm{l}$ of TaqMan PreAmp master mix $(2 \times), 12.5 \mu \mathrm{l}$ of the pooled assay mix $(0.2 \times), 10 \mu \mathrm{l}$ of cDNA sample $(2.5 \mathrm{ng} / \mu \mathrm{l})$ and $10 \mu \mathrm{l}$ of nuclease-free water. The preamplification reaction was performed for $10 \mathrm{~min}$ at $95^{\circ} \mathrm{C}$, and 10 cycles of $15 \mathrm{~s}$ at $95^{\circ} \mathrm{C}$ and $4 \mathrm{~min}$ at $60^{\circ} \mathrm{C}$ (PE 9600 GeneAmp PCR system Applied Biosystems).

\section{Taqman Gene Expression Reaction}

The thirteen gene expression assays (including one endogenous control) were diluted 1:5 (20-4×) using $1 \times$ TE buffer. The preamplified products were diluted 1:5 using TE buffer. The gene expression reaction was performed in $20 \mu \mathrm{l}$ reactions containing $10 \mu \mathrm{l}$ of TaqMan gene expression master mix w/UNG $(2 \times), 5 \mu \mathrm{l}$ of diluted preamp product and $5 \mu \mathrm{l}$ of TaqMan gene expression assay $(4 \times)$. The following thermal cycling specifications were performed on the ABI Prism ${ }^{\mathbb{R}} 7000$ sequence detection system (Applied Biosystems) $2 \mathrm{~min}$ at $50^{\circ} \mathrm{C}, 10 \mathrm{~min}$ at $95^{\circ} \mathrm{C}$ and 40 cycles each for $15 \mathrm{~s}$ at $95^{\circ} \mathrm{C}$ and $1 \mathrm{~min}$ at $60^{\circ} \mathrm{C}$.

\section{Results}

TaqMan PCR analysis was performed using the panel of assays (primers and probes) seen in

Table 1 Panel of assays (including $C D K N 1 B$ as the endogenous control) which were used to perform TaqMan ${ }^{\circledR}$ PCR analysis

\begin{tabular}{ll}
\hline Gene symbol & Gene name \\
\hline TOP2A & Topoisomerase II $\alpha$ \\
HLA-DQB1 & Major histocompatibility complex class II DQB1 \\
HLA-DMA & Major histocompatibility complex class II DMA \\
MT1K & Metallothionein 1M \\
TGFB1 & Transforming growth factor, $\beta$-1 \\
CSNK1G2 & Casein kinase 1, gamma 2 \\
KRAS2 & v-Ki-ras2 Kirsten rat sarcoma viral oncogene \\
& homologue \\
MT1X & Metallothionein 1X \\
RF3 & Interferon regulatory factor 3 \\
$C D$ B23 & RAB23, member RAS oncogene family \\
& CD74 molecule, major histocompatibility \\
LYN & complex, class II invariant chain \\
CDKN1B & v-yes-1 Yamaguchi sarcoma viral-related \\
& oncogene homologue \\
& Cyclin-dependent kinase inhibitor 1B
\end{tabular}

Table 1, including $C D K N 1 B$ as the endogenous control.

Analysis of relative gene expression data was performed using the $2^{-\Delta \Delta C_{T}}$ method with cyclindependent kinase inhibitor $1 \mathrm{~B}(C D K N 1 B)$ as the endogenous control/reference assay. This algorithm presents data as fold change in gene expression normalized to an endogenous reference gene. ${ }^{9}$ Non-parametric Mann-Whitney statistical analysis was performed (Analyse-it ${ }^{\circledR}$ statistical software for Microsoft ${ }^{\circledR}$ Excel $^{\mathbb{R}}$ ). Table 2 demonstrates targets which significantly discriminated benign from malignant groups. No significant difference was found between classic papillary thyroid carcinoma and follicular variant of papillary thyroid carcinoma groups or between follicular variant of papillary thyroid carcinoma and follicular thyroid carcinoma groups. Figure 1 demonstrates the $2^{-\Delta \Delta C_{T}}$ method data or relative quantification (RQ) data graphically represented as a box plot.

\section{Discussion}

The aim of this study was to validate the utility of a panel of molecular markers identified by microarray analysis, ${ }^{8}$ which we hypothesized could distinguish papillary thyroid carcinoma, follicular variant of papillary thyroid carcinoma, follicular thyroid carcinoma and follicular adenoma by their expression repertoires.

Table 2 Displays targets that significantly discriminated benign follicular adenoma (FA) from follicular variant of papillary thyroid carcinoma (FVPTC) (a) and follicular adenoma from follicular thyroid carcinoma (FTC) (b). (c) Demonstrates targets that significantly distinguished follicular adenoma from the papillary thyroid carcinoma (PTC) group (classic and follicular variants), while (d) displays the assay that showed a significant difference between papillary thyroid carcinoma and follicular thyroid carcinoma

\begin{tabular}{cc}
\hline Target & Two-tailed \\
P-value
\end{tabular}

$\begin{array}{lr}\text { (a) P-values for FA vs FVPTC } & \\ \text { MT1X } & 0.0015 \\ \text { CSNKIG2 } & 0.0124 \\ \text { RAB23 } & <0.0001 \\ \text { HLA-DMA } & 0.0390 \\ \text { HLA-DQB1 } & 0.0390 \\ & \\ \text { (b) P-values for FA vs FTC } & 0.05 \\ \text { MT1X } & 0.0446 \\ \text { MT1K } & 0.0149 \\ \text { RAB23 } & \\ \text { (c) P-values for FA vs PTC } & 0.0010 \\ \text { CSNK1G2 } & 0.0086 \\ \text { HLA-DQB1 } & <0.0001 \\ \text { MT1X } & <0.0001 \\ \text { RAB23 } & \\ \text { (d) P-value for FTC vs PTC } & \\ \text { KRAS2 } & 0.0382\end{array}$




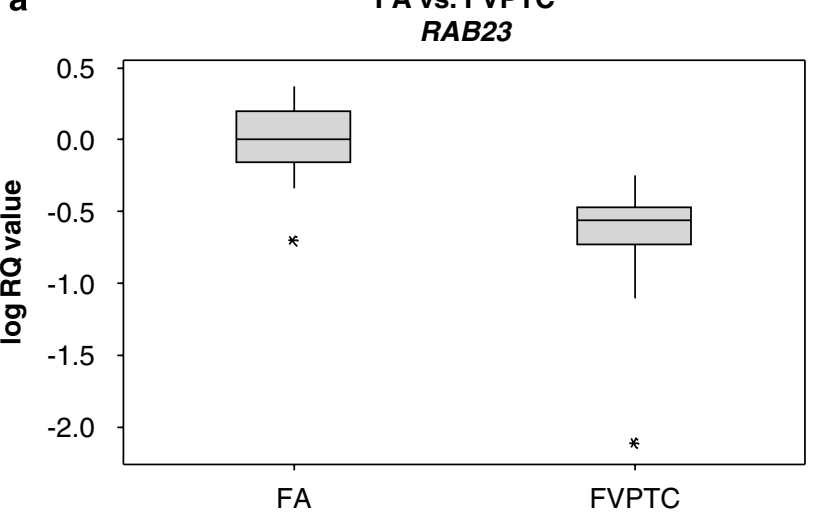

c

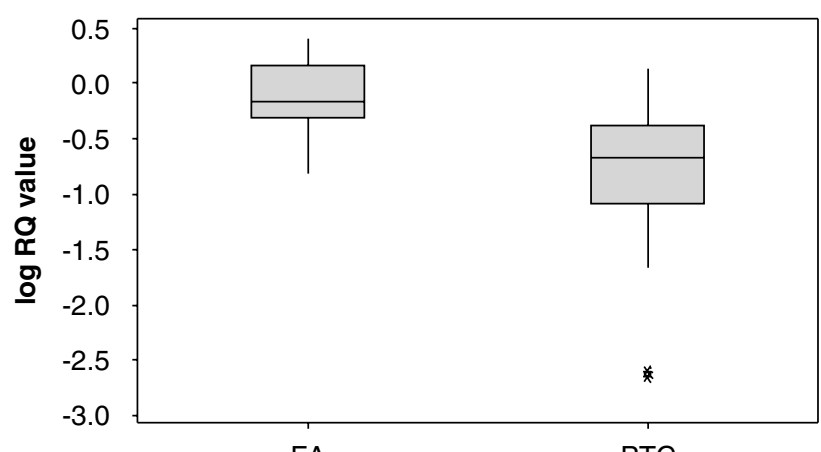

FA

e
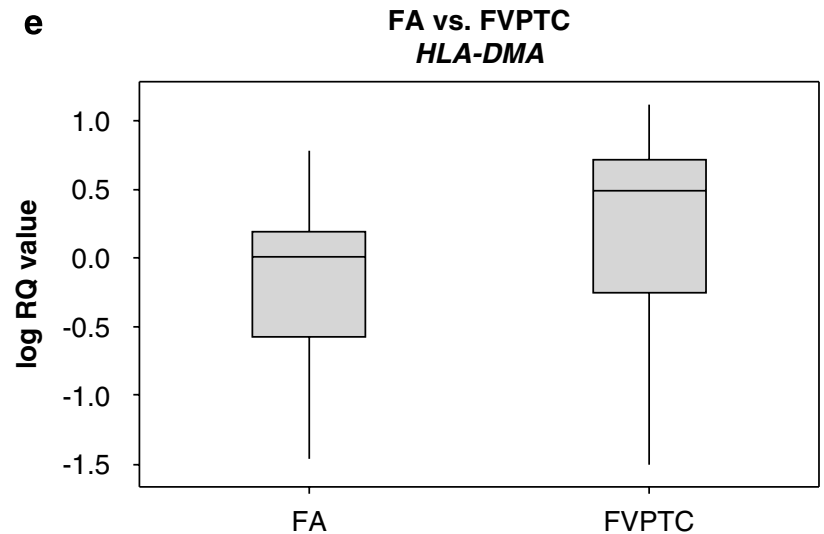

b

FA vs. FTC

RAB23

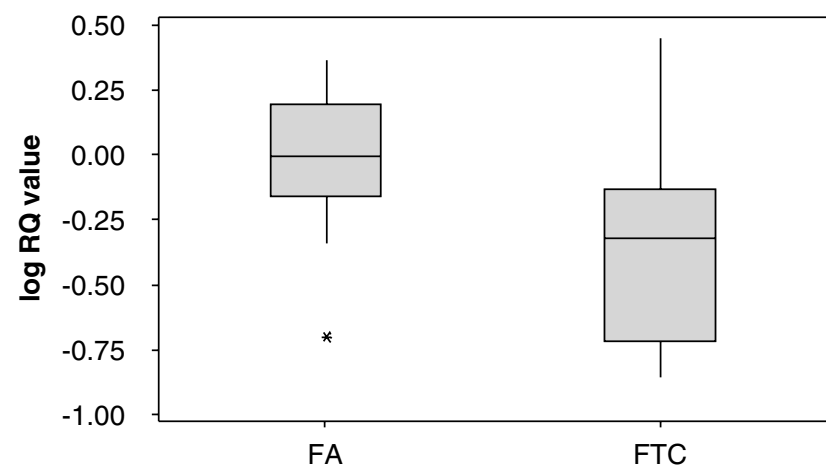

d

FA vs. FVPTC
CSNK1G2

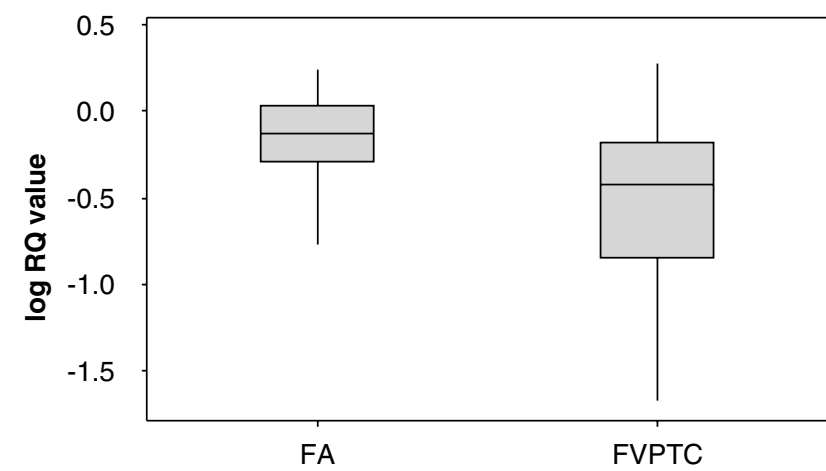

f

FA vs. PTC

HLA-DQB1

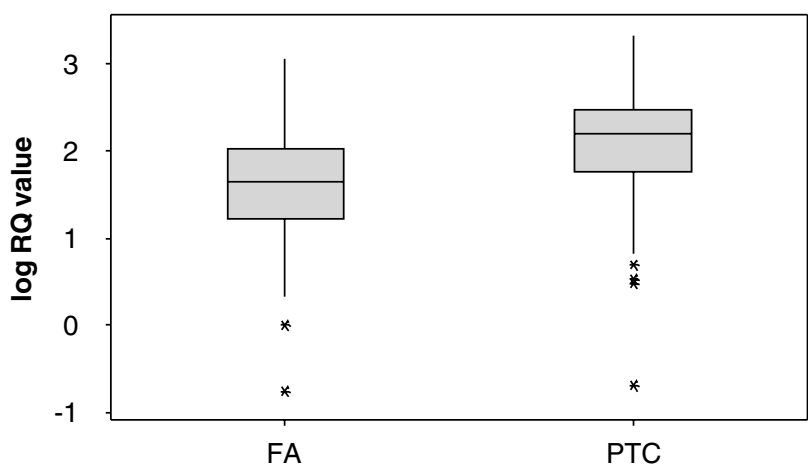

Figure 1 The $2^{-\Delta \Delta C_{T}}$ method data or RQ data graphically represented as a box plot. (a) Downregulation of Rab23 in the malignant follicular variant of papillary thyroid carcinoma (FVPTC) group in contrast to the benign follicular adenoma (FA) group $(P<0.0001)$. (b) Downregulation of Rab23 in the malignant cohort (follicular thyroid carcinoma (FTC)) compared to the benign follicular adenoma cohort $(P<0.0149)$. (c) Downregulation of $M T 1 X$ in the papillary thyroid carcinoma group (PTC) (classic and follicular variants) when compared to benign follicular adenoma $(P<0.0001)$. (d) Downregulation of CSNK1G2 in the follicular variant of papillary thyroid carcinoma group in contrast to the follicular adenoma category $(P<0.0124)$. (e and $\mathbf{f})$ Upregulation in expression of the MHC class II targets in the malignant papillary thyroid carcinoma cohorts. (e) Upregulation of HLA-DMA in follicular variant of papillary thyroid carcinoma in contrast to the benign follicular adenoma group $(P<0.0390)$. (f) Upregulation of $H L A-D Q B 1$ in the papillary thyroid carcinoma group (classic and follicular variants) compared to the follicular adenoma group $(P<0.0086)$. Asterisks $\left(^{*}\right)$ refer to outliers.

\section{Preamplification and Endogenous Control}

The panel was applied to a series $(n=72)$ of formalin-fixed paraffin-embedded archival tissue samples using laser capture microdissection as a means to retrieve homogenous cell populations of follicular epithelial cells. Although an accurate and precise technique, laser capture microdissection procures a small yield of RNA (yields in the range of $5-63 \mathrm{ng} / \mu \mathrm{l}$ were achieved in this study). Relative quantitative analysis was performed to determine relative gene expression levels in each sample. To this end, equal quantities of RNA were used in each sample. Consequently, only $5 \mathrm{ng} / \mu \mathrm{l}$ (or $0.125 \mu \mathrm{g}$ in 
$25 \mu \mathrm{l}$ ) of RNA was available from each sample for use in each individual assay. In the past, gene expression studies using archival material have been limited to analysis of few targets $(<4)$ in any given experiment. ${ }^{10-13}$ Limited quantities available from archival material become a greater issue when microdissection is introduced. While it is possible to repeat the preparation and microdissection using serial sections, this is time consuming and labour intensive, and requires pooling of extracts to achieve uniformity in analysis.

In this study, we successfully performed TaqMan ${ }^{\circledR}$ RT-PCR analysis on a panel of 13 assays using a total of $0.125 \mu \mathrm{g}$ of input RNA per sample. This increased sensitivity was achieved using a novel preamplification technique TaqMan $^{\circledR}$ PreAmp Master Mix, Applied Biosystems). The technique is intended for use with very small quantities of cDNA and facilitates multiplex preamplification up to 100plex. Moreover, it generates unbiased amplicons of specific regions of the starting cDNA to be analysed. In a separate study (data not shown) our group has compared parallel extracts from fresh-frozen paraffin-embedded and snap-frozen cell preparations using a normal thyroid cell line model applying the preamplification technique. The application of PreAmp lowered $C_{\mathrm{T}}$ values in snap-frozen and fresh-frozen paraffin-embedded material when compared to snap-frozen and fresh-frozen paraffinembedded tissues that were not preamplified. This increased sensitivity was consistent and reproducible indicating that preamplification does not distort relative expression levels rather it enhances sensitivity.

In selecting the endogenous control to be used as a normalizer in the study, two controls were initially proposed: glyceraldehyde-3-phosphate dehydrogenase $(G A P D H)$ and cyclin-dependent kinase inhibitor 1B $(C D K N 1 B)$. Preliminary data correlating preamplified with un-preamplified cDNA (data not shown) suggested that endogenous controls with an amplicon size similar to that of the assays to be utilized produced more reproducible expression data when parallel fresh and formalin-fixed samples were analysed. The pilot study compared amplicons over a range from 62 to $122 \mathrm{bp}$. In general, bias was introduced into the system when the amplicon size of the reference gene exceeded that of the target to be analysed. Given the commercially available $G A P D H$ is $122 \mathrm{bp}$, it was decided to revert to $C D K N 1 B(71 \mathrm{bp})$ for calculation of relative expression, given its unchanging expression levels across samples tested.

\section{Expression Patterns}

MT1K and MT1X are members of the metallothionein family. Metallothioneins are a group of low-molecular weight, cystein-rich intracellular proteins. MT1K and MT1X were downregulated in the follicular thyroid carcinoma group compared to follicular adenoma, while $M T 1 X$ was downregulated in the follicular variant of papillary thyroid carcinoma group compared to follicular adenoma. MT1X was downregulated in the papillary thyroid carcinoma group as a whole (classic and follicular variants) in contrast to the benign follicular adenoma group. To date, a number of microarray studies have shown metallothioneins to be downregulated in thyroid carcinoma. ${ }^{7,14,15}$ Huang et a $1^{14}$ expanded on their initial microarray experiment by trying to identify novel tumour suppressor genes involved in thyroid carcinogenesis. They found that $M T 1 G$ was downregulated in papillary thyroid carcinoma consequent to hypermethylation. In this study, metallothioneins were observed to be under-expressed in all of the malignant cohorts. This finding fortifies their candidacy as tumour suppressor genes in the setting of thyroid neoplasia.

Casein kinase I $\gamma 2$ (CSNKIG2) was downregulated in the follicular variant of papillary thyroid carcinoma group compared to the follicular adenoma group and was also downregulated in the combined papillary thyroid carcinoma group (classic and follicular variants) in contrast to the follicular adenoma group. Casein kinase I represents a unique group of serine/threonine protein kinases that are ubiquitously expressed in eukaryotic organisms. Studies have shown that rat CSNKIG2 directly interacts with Nck adaptor protein ${ }^{16,17}$ and human CSNKIG2 has 94\% homology with the rat homology. ${ }^{17}$ Nck is believed to act as an adaptor protein mediating signal transduction initiated by receptor tyrosine kinases, such as the insulin receptor, which has implications in the context of thyroid tumorigenesis as activation of the insulin receptor and other tyrosine kinase receptors are thought to play a role in thyroid cancer progression ${ }^{18,19}$ It is feasible that CSNKIG2 is the isoform responsible for attenuating the insulin-mediated signalling pathway by modifying the receptor directly. ${ }^{20}$ CSKNIG2 has also been shown to phosphorylate the ligand-activated platelet-derived growth factor receptor, a membrane protein-tyrosine kinase and result in its inactivation. ${ }^{21}$ Platelet-derived growth factor and the insulin receptor are essential for the regulation of cell growth and differentiation, factors which if were lost may result in cellular transformation. Marin et $a l^{22}$ showed that casein kinase I phosphorylates Ser-45 of $\beta$-catenin priming the subsequent phosphorylation by glycogen synthatase 3 that signals the degradation of $\beta$-catenin and prevents its function in triggering cell division in thyroid carcinoma. Furthermore, work by Garcia-Rostan et $a l^{23,24}$ has correlated mutations of the casein kinase I target phosphorylation site in $\beta$-catenin with thyroid tumours.

Downregulation of Rab23 was seen in three malignant cohorts; follicular thyroid carcinoma, papillary thyroid carcinoma and follicular variant of papillary thyroid carcinoma when compared with 
the benign follicular adenoma group. Highly significant $P$-values of $<0.0001$ were observed for the follicular variant of papillary thyroid carcinoma and papillary thyroid carcinoma groups when compared with follicular adenoma. Rab23 is a member of the Ras super family of small GTPases that function in the regulation of vesicular trafficking. In vertebrate neural systems, Rab23 acts as a negative regulator of hedgehog signalling. ${ }^{25,26}$ The hedgehog signalling cascade is pivotal to embryonic development, and is involved in patterning a diverse range of vertebrate structures. ${ }^{27}$ Aberrant activation of this pathway in postnatal life has been associated with a range of cancers including lung, prostate, colorectal and basal cell carcinomas of the skin. ${ }^{28-31}$ It is interesting to speculate that the absence of Rab23 and therefore the absence of a negative regulator of hedgehog signalling is implicated in the development of thyroid carcinoma.

KRAS2 was upregulated in the follicular thyroid carcinoma group when compared with the papillary thyroid carcinoma group as a whole (classic and follicular variants). Numerous studies have demonstrated RAS mutations in thyroid tumours. ${ }^{32}$ Activating mutations of all three RAS oncogenes (KRAS, HRAS and NRAS) have historically been associated with a higher frequency in follicular than in papillary tumours. ${ }^{33,34}$ A recent study by Carta et $a l^{35}$ found an absence of $R A S$ mutations in an Italian papillary thyroid carcinoma cohort but the presence of $R A S$ oncogenic mutations in $75 \%$ of follicular thyroid carcinomas.

\section{HLA Markers}

The pattern of expression in MHC class II assays in follicular variant of papillary thyroid carcinoma was noteworthy. Upregulated expression was established for $H L A-D M A$ and $H L A-D Q B 1$ genes in the follicular variant of papillary thyroid carcinoma group compared to follicular adenoma and upregulation of $H L A-D Q B 1$ was observed in the papillary thyroid carcinoma (classic and follicular) group compared to follicular adenoma. This finding corroborates an earlier observation by Finn et al who also found increased expression of class II MHC genes in follicular variant of papillary thyroid carcinoma. Furthermore, Hwang et $a l^{36}$ have demonstrated ret/PTC bearing papillary thyroid carcinoma cells that strongly express MHC class II (HLA-DRA) genes, although surrounding normal tissue did not. ret/PTC (rearranged in transformation/papillary thyroid carcinoma) is a constitutively active tyrosine kinase frequently found in papillary thyroid carcinoma and autoimmune Hashimoto's thyroiditis. ${ }^{37,38}$ This observation suggests that overexpression of MHC class II genes may represent a novel feature of malignant thyroid follicular epithelium, and may play a role in the evasion of the immune system.

\section{Applications}

Fine-needle aspiration, histology and cytology are widely used in the initial diagnosis of thyroid malignancy. However they are impaired by limitations, such as the inability to definitively differentiate follicular adenomas from follicular carcinomas. Sangalli et al's ${ }^{39}$ investigation into the efficacy of 5469 thyroid fine-needle aspirations found a worryingly high false-negative rate of $6.2 \%$, due to the failure to recognize follicular variant of papillary thyroid carcinoma. Inclusion of targets tested in this experiment into the routine testing protocol may provide useful adjunctive data in this setting. A number of groups have suggested molecular markers to assist in the diagnosis of papillary thyroid carcinoma from fine-needle aspiration specimens. ${ }^{40,41}$ Sapio et $a l^{42}$ recently proposed detection of ret/PTC, TRK and BRAF (V600E) in fine-needle aspiration specimens as a diagnostic adjunctive tool in the evaluation of thyroid nodules. They found that the discovery of oncogenes in fineneedle aspiration specimens suspicious for malignancy guided the extent of surgical resection, changing the surgery from diagnostic to therapeutic in five cases. The application of these markers to the diagnosis of follicular lesions in thyroid carcinoma may hopefully provide another approach in the challenging diagnosis of these lesions. Targets such as $R A B 23$ (Figure 1a, $P<0.001$ ) and $M T 1 X$ (Figure 1c, $P<0.001)$ showed better discriminatory power than some of the HLA markers (Figure 1e, $P=0.0390$ ) when displayed as box plots (Figure 1). While some overlap was observed in expression of certain HLA markers (HLA-DMA) comparing follicular adenoma and follicular variant of papillary thyroid carcinoma cohorts, it should be noted that the data are presented using a log scale. It is also noteworthy that there is a significant difference between medians in these groups for these markers. The presence of outlying data, while potentially diminishing the statistical significance of the data should not detract from the biological significance of aberrant HLA expression in the follicular variant of papillary thyroid carcinoma population.

In this experiment, we set out to validate the efficacy of a panel of markers identified through microarray analysis ${ }^{8}$ by its application to a large series of archival benign and malignant thyroid lesions. Laser Capture Microdissection was employed to obtain homogenous populations of follicular epithelial cells. Any impediment due to low RNA yields from small cell numbers was surmounted using a novel preamplification technique that allowed interrogation of a large panel of targets in the study cohort. This study not only demonstrates the ability to draw on the substantial archive of formalin-fixed paraffin-embedded tissue available and to analyse samples with unbiased preamplification, but it also highlights seven gene targets that have robustly discriminated between subgroups of 
thyroid lesions. There is scope for this panel to be further refined to include other gene targets proposed by microarray analysis. Future directions for this work may include further insight into the proposed tumour suppressor genes, in particular casein kinase I $\gamma 2$ as it appears to play a role in the activation of the insulin receptor and other tyrosine kinase receptors which are thought to be involved in thyroid cancer progression. Also further rationale is needed to explain the aberrant expression of the MHC II genes $H L A-D M A$ and $H L A-D Q B 1$, as these could stand to represent a novel feature of malignant thyroid follicular epithelium.

Nonetheless, the study has established proof of principle that expression analysis may be reliably performed using a panel of markers in archival samples and this strategy may prove valuable as an adjunctive analytical tool in the diagnostic setting.

\section{Disclosure}

KD, PS, SC, SF, EC, JHL, RF, SA, JO'L and OS have nothing to declare. SG and AF are employed by Applied Biosystems.

\section{References}

1 Liu J, Singh B, Tallini G, et al. Follicular variant of papillary thyroid carcinoma: a clinicopathologic study of a problematic entity. Cancer 2006;107:1255-1264.

2 Lote K, Andersen K, Nordal E, et al. Familial occurrence of papillary thyroid carcinoma. Cancer 1980;46:1291-1297.

3 DeLellis R, Lloyd RV, Heitz PU. WHO classification of thyroid and parathyroid tumours WHO classification of tumours. PatholGenet Tumours Endocrine Organs 2004;8:49-123.

4 Schmid KW, Farid NR. How to define follicular thyroid carcinoma? Virchows Arch 2006;448:385-393.

5 Rosai J, Carcargiu ML, Delellis RA. Follicular carcinomas. Papillary carcinomas. In: Rosai J, Sobin LH (eds). Tumors of the Thyroid Gland Atlas of Tumor Pathology. Armed Forces Institute of Pathology: Washington, DC, USA, 1992, pp 49-121.

6 Baloch Z, Livolsi VA. Pathology. In: Braverman LE, Utiger RD (eds). The Thyroid A Fundamental and Clinical Text, 9th edn. Lippincott Williams and Wilkins: Philadelphia, 2005, pp 422-449.

7 Barden CB, Shister KW, Zhu B, et al. Classification of follicular thyroid tumors by molecular signature: results of gene profiling. Clin Cancer Res 2003;9: 1792-1800.

8 Finn SP, Smyth P, Cahill S, et al. Expression microarray analysis of papillary thyroid carcinoma and benign thyroid tissue: emphasis on the follicular variant and potential markers of malignancy. Virchows Arch 2007;450:249-260.

9 Livak KJ, Schmittgen TD. Analysis of relative gene expression data using real-time quantitative PCR and the 2(-Delta Delta C(T)) Method. Methods 2001;25: $402-408$.
10 Kuramochi H, Hayashi K, Uchida K, et al. Vascular endothelial growth factor messenger RNA expression level is preserved in liver metastases compared with corresponding primary colorectal cancer. Clin Cancer Res 2006;12:29-33.

11 Azuma M, Danenberg KD, Iqbal S, et al. Epidermal growth factor receptor and epidermal growth factor receptor variant III gene expression in metastatic colorectal cancer. Clin Colorectal Cancer 2006;6: 214-218.

12 Chen CL, Ou DL. Expression of syndecan-1 (CD138) in nasopharyngeal carcinoma is correlated with advanced stage and poor prognosis. Hum Pathol 2006;37: 1279-1285.

13 Vernooy JH, Moller GM, van Suylen RJ, et al. Increased granzyme A expression in type II pneumocytes of patients with severe chronic obstructive pulmonary disease. Am J Respir Crit Care Med 2007;175:464-472.

14 Huang Y, Prasad M, Lemon WJ, et al. Gene expression in papillary thyroid carcinoma reveals highly consistent profiles. Proc Natl Acad Sci USA 2001;98: 15044-15049.

15 Finley DJ, Arora N, Zhu B, et al. Molecular profiling distinguishes papillary carcinoma from benign thyroid nodules. J Clin Endocrinol Metab 2004;89:3214-3223.

16 Lussier G, Larose L. A casein kinase I activity is constitutively associated with Nck. J Biol Chem 1997; 272:2688-2694.

17 Kitabayashi AN, Kusuda J, Hirai M, et al. Cloning and chromosomal mapping of human casein kinase I gamma 2 (CSNK1G2). Genomics 1997;46:133-137.

18 Miyagi E, Braga-Basaria M, Hardy E, et al. Chronic expression of RET/PTC 3 enhances basal and insulinstimulated PI3 kinase/AKT signaling and increases IRS-2 expression in FRTL-5 thyroid cells. Mol Carcinog 2004;41:98-107.

19 Frittitta L, Sciacca L, Catalfamo R, et al. Functional insulin receptors are overexpressed in thyroid tumors: is this an early event in thyroid tumorigenesis? Cancer 1999;85:492-498.

20 Gross SD, Anderson RA. Casein kinase I: spatial organization and positioning of a multifunctional protein kinase family. Cell Signal 1998;10:699-711.

21 Bioukar EB, Marricco NC, Zuo D, et al. Serine phosphorylation of the ligand-activated beta-plateletderived growth factor receptor by casein kinase Igamma2 inhibits the receptor's autophosphorylating activity. J Biol Chem 1999;274:21457-21463.

22 Marin O, Bustos VH, Cesaro L, et al. A noncanonical sequence phosphorylated by casein kinase 1 in betacatenin may play a role in casein kinase 1 targeting of important signaling proteins. Proc Natl Acad Sci USA 2003;100:10193-10200.

23 Garcia-Rostan G, Camp RL, Herrero A, et al. Betacatenin dysregulation in thyroid neoplasms: downregulation, aberrant nuclear expression, and CTNNB1 exon 3 mutations are markers for aggressive tumor phenotypes and poor prognosis. Am J Pathol 2001;158:987-996.

24 Garcia-Rostan G, Tallini G, Herrero A, et al. Frequent mutation and nuclear localization of beta-catenin in anaplastic thyroid carcinoma. Cancer Res 1999;59: 1811-1815.

25 Evans TM, Simpson F, Parton RG, et al. Characterization of Rab23, a negative regulator of sonic hedgehog signaling. Methods Enzymol 2005;403:759-777. 
26 Eggenschwiler JT, Espinoza E, Anderson KV. Rab23 is an essential negative regulator of the mouse Sonic hedgehog signalling pathway. Nature 2001;412: 194-198.

27 Wicking C, McGlinn E. The role of hedgehog signalling in tumorigenesis. Cancer Lett 2001;173: $1-7$.

28 Daniel VC, Peacock CD, Watkins DN. Developmental signalling pathways in lung cancer. Respirology 2006; 11:234-240.

29 Karhadkar SS, Bova GS, Abdallah N, et al. Hedgehog signalling in prostate regeneration, neoplasia and metastasis. Nature 2004;431:707-712.

30 Akiyoshi T, Nakamura M, Koga K, et al. Gli1, downregulated in colorectal cancers, inhibits proliferation of colon cancer cells involving Wnt signalling activation. Gut 2006;55:991-999.

31 Athar M, Tang X, Lee JL, et al. Hedgehog signalling in skin development and cancer. Exp Dermatol 2006;15: 667-677.

32 Suarez HG. Genetic alterations in human epithelial thyroid tumours. Clin Endocrinol (Oxford) 1998;48: 531-546.

33 Suarez HG, Du Villard JA, Caillou B, et al. Detection of activated ras oncogenes in human thyroid carcinomas. Oncogene 1988;2:403-406.

34 Lemoine NR, Mayall ES, Wyllie FS, et al. Activated ras oncogenes in human thyroid cancers. Cancer Res 1988;48:4459-4463.

35 Carta C, Moretti S, Passeri L, et al. Genotyping of an Italian papillary thyroid carcinoma cohort revealed high prevalence of BRAF mutations, absence of RAS mutations and allowed the detection of a new mutation of BRAF oncoprotein (BRAF(V599lns)). Clin Endocrinol (Oxford) 2006;64:105-109.

36 Hwang ES, Kim DW, Hwang JH, et al. Regulation of signal transducer and activator of transcription 1 (STAT1) and STAT1-dependent genes by RET/PTC (rearranged in transformation/papillary thyroid carcinoma) oncogenic tyrosine kinases. Mol Endocrinol 2004;18:2672-2684.

37 Sheils OM, O'Eary JJ, Uhlmann V, et al. ret/PTC-1 activation in hashimoto thyroiditis. Int J Surg Pathol 2000;8:185-189.

38 Hunt JL, Baloch ZW, Barnes L, et al. Loss of heterozygosity mutations of tumor suppressor genes in cytologically atypical areas in chronic lymphocytic thyroiditis. Endocr Pathol 2002;13:321-330.

39 Sangalli G, Serio G, Zampatti C, et al. Fine needle aspiration cytology of the thyroid: a comparison of 5469 cytological and final histological diagnoses. Cytopathology 2006;17:245-250.

40 Cheung CC, Carydis B, Ezzat S, et al. Analysis of ret/PTC gene rearrangements refines the fine needle aspiration diagnosis of thyroid cancer. J Clin Endocrinol Metab 2001;86:2187-2190.

41 Salvatore G, Giannini R, Faviana P, et al. Analysis of BRAF point mutation and RET/PTC rearrangement refines the fine-needle aspiration diagnosis of papillary thyroid carcinoma. J Clin Endocrinol Metab 2004; 89:5175-5180.

42 Sapio MR, Posca D, Raggioli A, et al. Detection of RET/PTC, TRK and BRAF mutations in preoperative diagnosis of thyroid nodules with indeterminate cytological findings. Clin Endocrinol (Oxford) 2007; 66:678-683. 